\title{
Optimization of the Shell Thickness of the ZnO/CdS Core-Shell Nanowire Arrays in a CZTS Absorber
}

\author{
Chonge Wang, Boubacar Drame $(\mathbb{D}$, Lucien Niare, and Fu Yuegang \\ School of Optoelectronic Engineering, Changchun University of Science and Technology, 7089 Weixing Rd, \\ Changchun, Jilin, China \\ Correspondence should be addressed to Boubacar Drame; boubacardrame66712232@gmail.com
}

Received 17 November 2021; Revised 29 December 2021; Accepted 31 December 2021; Published 20 January 2022

Academic Editor: Sulaiman W. Harun

Copyright $(92022$ Chonge Wang et al. This is an open access article distributed under the Creative Commons Attribution License, which permits unrestricted use, distribution, and reproduction in any medium, provided the original work is properly cited.

Copper-zinc-tin-sulfide (CZTS) solar cells have now become a topic of interest in the solar power generation industry. These are used as an absorber in the zinc oxide $(\mathrm{ZnO}) / \mathrm{cadmium}$ sulfide $(\mathrm{CdS})$ core-shell nanowire arrays, in order to improve the performance of solar cells. The relationship between the average increase in absorption rates and CdS shell thickness (compared to the thin film) reveals that the optimum thickness with the maximum average absorption rate (39.95\%) compared to thin film is $30 \mathrm{~nm}$. The cells' electrical and optical performance was significantly improved with the introduction of graphene between the $\mathrm{ZnO}$ and CdS layers. The shell thicknesses for a better performance of these nanowire solar cells were 30 and $40 \mathrm{~nm}$, with almost the same open-circuit voltage, the similar short-circuit current density, and efficiency, which were $630 \mathrm{mV}, 6.39 \mathrm{~mA} / \mathrm{cm}^{2}$, and $16.8 \%$, respectively. Furthermore, a minimum reflection of $40 \%$ was obtained with these same shell thicknesses.

\section{Introduction}

In recent decades, copper-zinc-tin-sulfide (CZTS) has emerged as an excellent absorber used in thin-film solar cells [1-3]. The use of nanotechnology has increased efficiency while reducing the cost of solar cells [4]. In addition, CZTS has a bandgap between 1.45 and $1.65 \mathrm{eV}$ along with a high absorption coefficient of more than $10^{4} \mathrm{~cm}^{-1}$ and a refractive index of 2.72 [5-9]. It can be obtained by cospraying copper $(\mathrm{Cu})$, tin (II), sulfide $(\mathrm{SnS})$, and zinc sulfide $(\mathrm{ZnS})$ for the deposition of precursors and followed by sulfurization in a hydrogen sulfide $\left(\mathrm{H}_{2} \mathrm{~S}\right)$ atmosphere [9], or by spraying metal precursors Copper-zinc-tin (Cu-Zn-Sn) from a single target, followed by vaporization of sulfur [10].

On the other hand, in recent decades, there has been an increasing interest in nanowire solar cells because of their ability to achieve high absorption and low reflection $[11,12]$. At room temperature, shell-less $\mathrm{ZnO}$ nanowire arrays are not very favorable for good absorption due to their wide bandgap of $3.3 \mathrm{eV}$. However, these can help improve the efficiency of photo-conversion if covered with an extremely thin shell of semiabsorbent conductors, such as CdS and graphene, owing to the fact that these $\mathrm{ZnO}$ nanowires have good conductivity, chemical stability, and long service life $[11,13,14]$.

Photocatalytic studies have shown that the $\mathrm{ZnO} / \mathrm{CdS}$ core-shell nanorod arrays exhibit a strong enhancement in degradation efficiency as compared to $\mathrm{ZnO}$ and $\mathrm{CdS}$ in the individual form under simulated solar radiation [15]. CdS is used for the core-shell, although it contains cadmium (Cd; a toxic product) because it reduces the junction area [16] and improves the interface with the absorber while ensuring a strong transmission in the region of certain wavelengths. It has a bandgap of $2.4 \mathrm{eV}$, efficient absorption in the wavelength of 380 to $510 \mathrm{~nm}$, and the advantage of wide bandgaps of $\mathrm{ZnO}$ and CdS. In this process, the majority of the photons are absorbed in the narrow-space p-type absorber (CZTS) [17]. Meng Ding et al. has also shown that the photocurrent in the ZnO@CdS heterostructure, with a core diameter of $100 \mathrm{~nm}$ and a shell thickness between $50 \mathrm{~nm}$ and $100 \mathrm{~nm}$, is $10^{2}$ times better than that in bare $\mathrm{ZnO}$ nanorods. On the other hand, the photoelectrochemical study on nanowire solar cells has shown that there are more free carriers generated and transferred in the $\mathrm{ZnO@CdS}$ heterostructure, 
leading to high separation efficiency than bare $\mathrm{ZnO}$ nanowires [18]. Likewise, in another study, Kim Dinh Hoang et al. showed that for an unpolarized incoming wave, a maximum weighted absorption efficiency of $90 \%$ is obtained with bare $\mathrm{ZnO}$ nanowires having a diameter of $110 \mathrm{~nm}$ against $93 \%$ for $\mathrm{ZnO} / \mathrm{CdS}$ core-shell nanowires with a core diameter and shell thicknesses of 88 and $20 \mathrm{~nm}$, respectively [19]. Another experiment on solar cells with arrays of $\mathrm{ZnO} / \mathrm{CdS}$ core-shell nanowires integrated into a $\mathrm{Cu}_{2} \mathrm{ZnSnS}_{4}$ absorber yielded a short-circuit current density of $0.70 \mathrm{~mA} / \mathrm{cm}^{2}$, an open-circuit voltage of $171.7 \mathrm{mV}$, a fill factor of $29.41 \%$, and an efficiency of $0.035 \%$. According to the analysis of the results of this experiment, the low efficiency may have resulted from the layer of $\mathrm{MoS}_{2}$ developed during sulfurization, increase in recombination of charge carriers at the rear contact (due to secondary phases in the interface), and a low thickness of the CZTS film [10]. In more detail, Qian Li et al. showed by surface analyzes of the CZTS that the high temperature $\left(580^{\circ} \mathrm{C}\right)$ of sulfurization leads to the complete disappearance of the secondary phases (improvement of the performance of the CZTS-based solar cell). As a result of this, a forbidden band of $1.48 \mathrm{eV}$ close to the theoretical value of $1.5 \mathrm{eV}$, an open-circuit voltage (Voc) of $583 \mathrm{mV}$, a short-circuit density (Jsc) of $7.32 \mathrm{~mA} / \mathrm{cm}^{2}$, a factor fill (FF) of $48.86 \%$, and a conversion efficiency of $2.08 \%$ is obtained [20]. Furthermore, an experiment conducted by Thomas Edwards et al. [21] on the $\mathrm{TiO}_{2} /$ CdSe core-shell solar cell has shown that nanowire core-shell solar cells, having a core diameter and shell thickness of approximately $80 \mathrm{~nm}$ and close to $30 \mathrm{~nm}$, respectively, can have an absorption efficiency close to $100 \%$ [21].

Thus, it is very important to emphasize that the simultaneous research on the control of the $\mathrm{MoS}_{2}$ layer developed during the sulfurization and the optimization of the geometric parameters of the model structure has to be deepened. To improve the performance of cell while taking into account the above information, models based on the CZTS thin-film solar cell and having $\mathrm{ZnO} / \mathrm{CdS}$ as core-shell nanowires have been compared in this research. The models studied are based on the $\mathrm{ZnO} / \mathrm{CdS} / \mathrm{CZTS}$ structure, and recent studies on such a structure have shown that the selection of the thicknesses of the different structural layers is one of the determining factors for improving the performance parameters of the cell [22]. Therefore, the current study has focused on the optimization of the geometric parameters, the design, and the composition of the model for the improvement of the performance of the solar cell.

\section{Materials and Methods}

To obtain the optical performances of the different models, simulation was performed using the COMSOL Multiphysics software on the thin-film solar cell and different nanowire solar cells by modifying the shell thickness. Research studies have shown that the best performance of solar cells was obtained at the angles of incidence between $0^{\circ}$ and $60^{\circ}$. So this simulation was based on the angle of incidence of $0^{\circ}$. This work studied thin-film and $\mathrm{ZnO} / \mathrm{CdS}$ core-shell nanowire models of CZTS solar cells, focusing first on the electric field distribution and optical properties, then on the efficiencies and optimal CdS shell thickness. Since studies of core-shell nanowire arrays have shown particular interest for a shell thickness of $30 \mathrm{~nm}$ [15], our initial study also focused on the CdS shell thickness of $70 \mathrm{~nm}$ for the model. With the $\mathrm{ZnO} / \mathrm{CdS}$ core-shell nanowires, the simulation study was carried out with CdS shell thicknesses of $30 \mathrm{~nm}, 100 \mathrm{~nm}$, and without CdS shell (CdS shell thickness of $0 \mathrm{~nm}$ ).

The geometric fill factor was computed as $\mathrm{FF}=\pi D^{2} / 4 P^{2}$, where $D$ is the sum of the diameter of $\mathrm{ZnO}$ nanowires, double CdS shell thickness, and double graphene shell and $P$ is kept at $360 \mathrm{~nm}$ (the pitch of nanowires). The two models are based on a square base of $3 \times 3 \mu \mathrm{m}$. Graphene was also used to improve the electronic mobility, conductivity, photocurrent generation, and capacitance of the two following models: $\mathrm{CdS}$ and $\mathrm{ZnO}[23,24]$. In addition, to increase the optical conductivity and the carrier mobility of the cell, graphene thickness of one nm was selected for the simulation [25].

Figure 1(a) shows the thin film device having a structure in the direction $Z$, which is $\mathrm{ZnO} /$ graphene/CdS/CZTS with the respective thicknesses of $100 \mathrm{~nm}, 1 \mathrm{~nm}, 100 \mathrm{~nm}$, and $1,000 \mathrm{~nm}$. Figure 1(b) shows the structure of nanowires having $\mathrm{ZnO}$ (diameter of $100 \mathrm{~nm}$, with $1,000 \mathrm{~nm}$ in length and $360 \mathrm{~nm}$ spacing), covered with a graphene shell thickness of $1 \mathrm{~nm}$ that is further covered with a CdS shell (thickness of $30 \mathrm{~nm}, 70 \mathrm{~nm}$, and $100 \mathrm{~nm}$ ). The free space between the nanowires was filled with CZTS film. The thickness of the bottom CdS layer was $100 \mathrm{~nm}$. Figure 2 shows the solar cell architectures of the optimized global thin-film (Figure 2(a)) and nanowire (Figure 2(b)) models. Weiwei Sun et al. conducted an experimental study on these two types of models (thin films and $\mathrm{ZnO} / \mathrm{CdS}$ core-shell nanowires), without graphene and with a CdS shell thickness of $70 \mathrm{~nm}$, The values $171.7 \mathrm{mV}, 0.7 \mathrm{~mA} / \mathrm{cm}^{2}, 0.035 \%$, and $54 \%$ were obtained as open-circuit voltage, the short-circuit current density, the efficiency, and the average absorption in the nanowires, respectively, which are not very significant [10].

In this work, for solar lighting, we considered the Solar Irradiance Spectra of Air Mass (AM1.5) [26], having a solar zenith angle of $48.2^{\circ}$.

COMSOL Multiphysics was used in this work for simulation studies. A finite element method was used to solve the electromagnetic fields in the modeling field. It is one of the best optical simulation software because it offers the possibility of modeling with different dimensions (1D, 2D, and 3D), by coupling with other physics, in particular optical, thermal, reaction-diffusion, etc. [27, 28]. Assuming $E$ $(\lambda)$ is a vector of the electric field in $3 \mathrm{D}$; the absorption $A(\lambda)$ was obtained by Aghaeipour and Pettersson [29]:

$$
A(\lambda)=\frac{1}{2} \int \frac{2 \pi \varepsilon_{0} c}{\lambda}|E(\lambda)|^{2} \operatorname{Im}\left(n^{2}(\lambda)\right) \mathrm{d} V
$$

where $\varepsilon_{0}\left(8.85 \times 10^{-12} \mathrm{~F} \cdot \mathrm{m}^{-1}\right)$ is the vacuum permittivity, $c(299792458 \mathrm{~m} / \mathrm{s})$ is the speed of light in vacuum, $\lambda$ is the photon wavelength, and $n$ represents the complex refractive index. The incident light transmits $T(\lambda)$ and the reflection $R(\lambda)$ on the substrate can be obtained by energy conservation through the following relation [30]: 


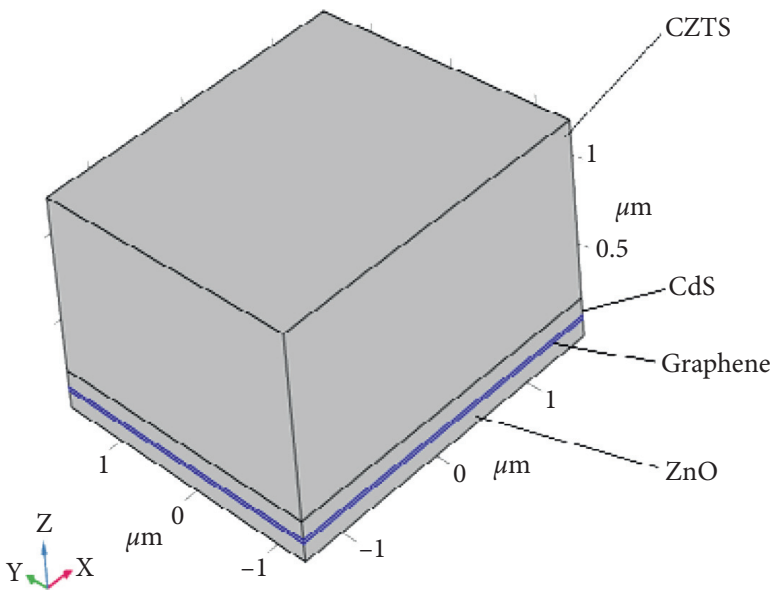

(a)

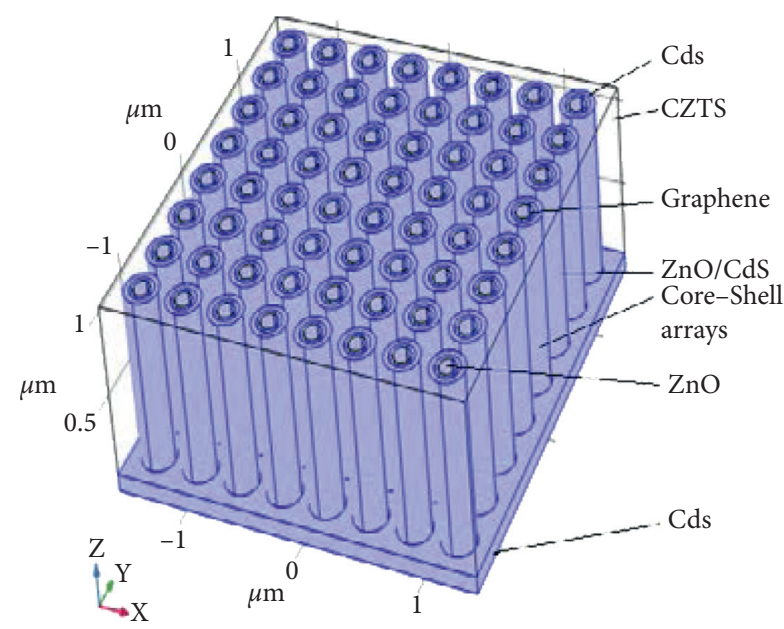

(b)

Figure 1: Structure models of (a) thin-film solar cells of $\mathrm{ZnO} /$ graphene/CdS/CZTS and (b) nanowire solar cell of ZnO/CdS core-shell array in CZTS film.

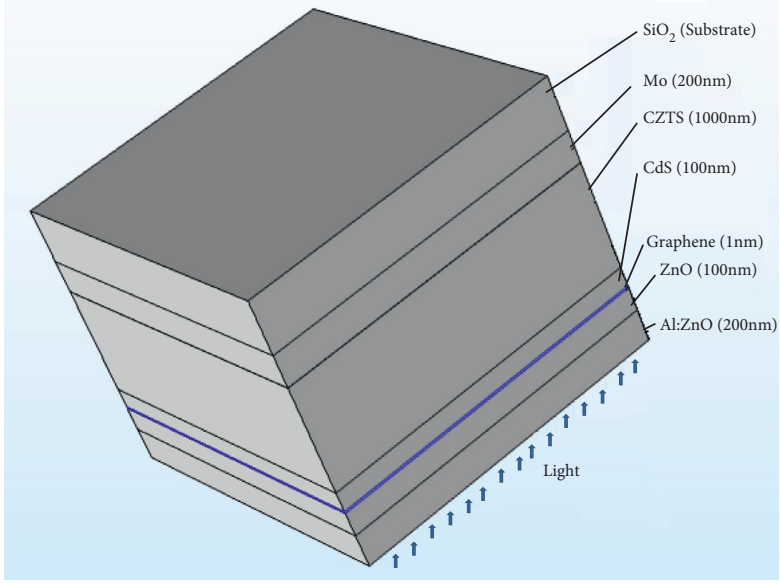

(a)

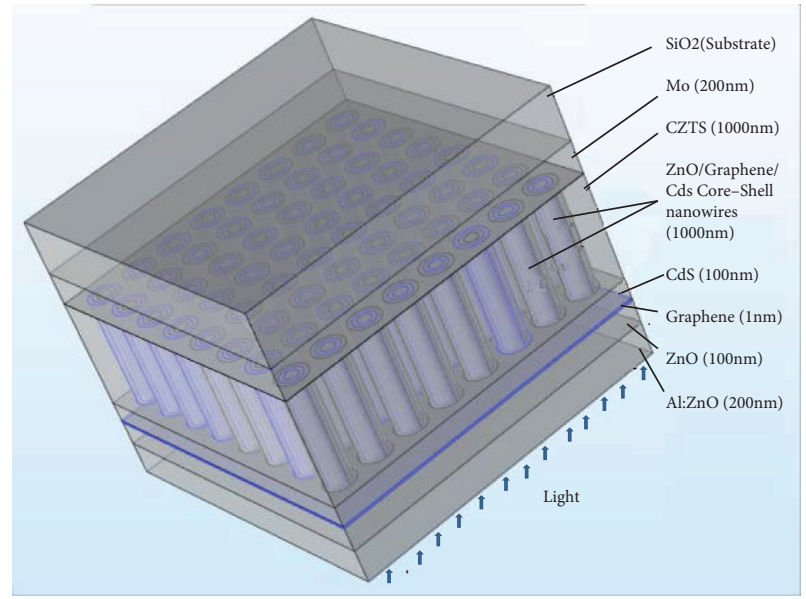

(b)

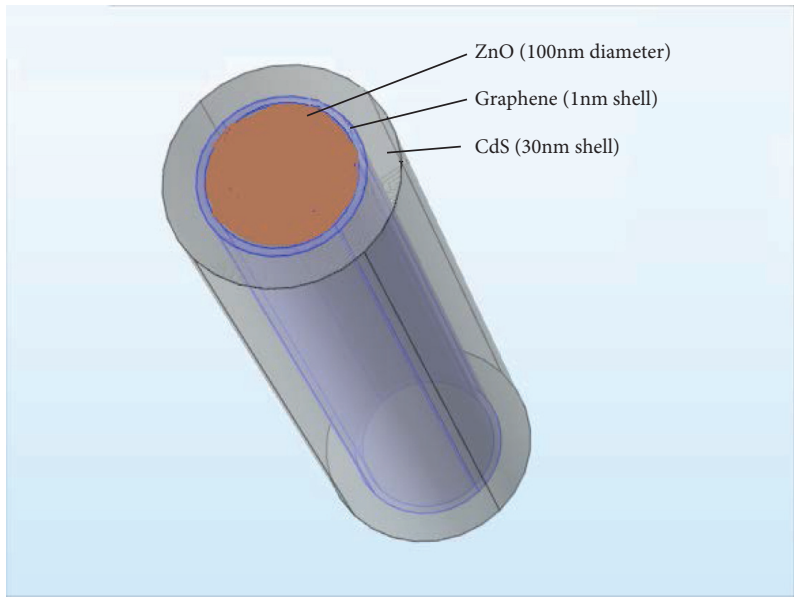

(c)

Figure 2: Optimized full model architectures of (a) thin film, (b) core-shell nanowires of CZTS solar cells, and (c) single core-shell nanowire architecture. 


$$
R(\lambda)=1-A(\lambda)-T(\lambda)
$$

To evaluate the absorption in the $\mathrm{ZnO} / \mathrm{CdS}$ core-shell nanowires, we calculated for each shell thickness the ultimate absorption efficiency $\eta$ according to the following formula [31]:

$$
\eta=\frac{\int_{\lambda_{l}}^{\lambda_{g}} I(\lambda) A(\lambda) \lambda / \lambda_{g} \mathrm{~d} \lambda}{\int_{\lambda_{l}}^{\lambda_{u}} I(\lambda) \mathrm{d} \lambda}
$$

where $I(\lambda)$ is the solar spectral irradiance, $\lambda_{l}$ is negligible solar irradiance $(300 \mathrm{~nm}), \lambda_{u}(4,000 \mathrm{~nm})$ represents the upper limit of the available data for the solar spectrum, and $\lambda_{g}(460 \mathrm{~nm})$ is the photon wavelength corresponding to the average bandgap of the materials of the model. The shortcircuit current and open-circuit voltage give an opportunity to evaluate the electrical performance of the solar cell. By Shockley's diode equation as a function of voltage, the current density $J$ is defined as follows [32]:

$$
J(V)=J_{0}\left(\exp \frac{e V}{K} T-1\right)-J_{\text {sc }}
$$

where $j_{0}$ is saturation current density, $V$ is the applied bias voltage, $\mathrm{kT} / e$ is the thermal voltage equal to $25.69 \mathrm{mV}$ at $25^{\circ} \mathrm{C}$, and $J_{\mathrm{SC}}$ is the short current density under illumination. The effective refractive index was computed with the calculation of the refractive index in the nanowires. The effective refractive index of $\mathrm{ZnO} / \mathrm{CdS}$ core-shell nanowires having free spaces filled with CZTS was given by the following equation [30]:

$$
n_{\mathrm{eff}}=n_{\mathrm{CZTS}}(1-\mathrm{FF})+n_{\mathrm{CS}} \mathrm{FF} \text {, }
$$

where $n_{\text {CZTS }}$ represents the refractive index of CZTS and $n_{\text {CS }}$ shows the refractive index of $\mathrm{ZnO}, \mathrm{CdS}$, and graphene block.

Figure 3 shows the schematic structures of both simulation models. The transverse magnetic (TM) field source was done by setting the port limit and setting it as a "periodic port." Figures 3(a) and 3(b) show a schematic diagram of the port location. The upper limit creates a "harbor wave excitation," which means incident light. To reduce the workload and complexity of calculations, "periodic conditions" were defined to obtain data. As shown in Figures 3(b) and $3(\mathrm{c})$, the two opposite limits were defined in the "periodic condition1." Finally, the other two faces of the simulation region were also defined under boundary conditions. The periodic type selects the "Floquet period," and its vector $k$ was derived from the periodic port. The simulation region was set as "swept mesh" for the air region and "freely divided tetrahedral mesh" for other regions (Figures 3(e) and 3(f)). For this physical interface, the maximum size of the cells of the grid was preferably less than a certain fraction of the wavelength. The incident light wavelength range for the current simulation model was 200 to $2,000 \mathrm{~nm}$, so the maximum cell size was $80 \mathrm{~nm}$ and the minimum cell size was $8 \mathrm{~nm}$. All simulation models used the same grid cell size to maintain computational rigor. In "Parameters1" of the global definition, $0 \mathrm{~nm}$ (not CdS-shell thickness), 30, 70, and $100 \mathrm{~nm}$ were selected as the values of CdS-shell thickness. A $500 \mathrm{~nm}$ layer has also been added to each of the above models to take an account of air parameters in the simulation.

In the magnetic propagation wave, the diffusion parameters were determined by parameter $S$ in terms of the electric field. The electromagnetic and electric fields acting on the ports can be calculated after the excitation of port1. The electric fields E1 and E2, respectively, at ports 1 and 2, are therefore transformed into a complex scalar quantity corresponding to the voltage. It was assumed that the fields are normalized with respect to the integrity of the energy flow through each cross-section of the ports. The electric field Ec calculated at port 1 also contains the reflected field. The distribution of the electric field in the model was calculated by setting the wavelength at $500 \mathrm{~nm}$. The coefficient of reflection (S11) and transmission (S21) were automatically calculated according to the equations (10) and (12), respectively [33]. The results of equation (1) were verified by equation (2), and the margin of error between the two curves from $200 \mathrm{~nm}$ to $2,000 \mathrm{~nm}$ is less than $1 \%$. The current density was calculated and then plotted according to equation (4). The ultimate absorption efficiency was calculated by equation (3). To evaluate the improvement in the absorption ratio due to the shell thickness of the CdS nanowires compared to the thin film, the average absorption value was calculated between the wavelengths $\lambda_{0}$ and $\lambda_{l}$ by using the equation as follows [34]:

$$
\bar{A}=\frac{1}{\lambda_{l}-\lambda_{0}} \int_{\lambda_{0}}^{\lambda_{l}} A(\lambda) \mathrm{d} \lambda,
$$

where $\lambda_{0}=200 \mathrm{~nm}$ and $\lambda_{l}=2000 \mathrm{~nm}$.

Since the average absorption of CdS core-shell nanowires was greater than the average absorption of the thin film. In order to assess this difference, the average increase in absorption rate of CdS core-shell nanowires (with the increasing shell thickness) compared to thin film $p$ was determined by the following equation [35]:

$$
R_{i}=\frac{\bar{A}_{i}-\bar{A}_{p}}{\bar{A}_{p}},
$$

where $\bar{A}_{i}$ and $\bar{A}_{p}$ are the average absorptions in the coreshell nanowires of CdS shell thickness and in the thin film of respective indices $i$ and $p$. Taking into account the simulation data, interpolation was performed, in order to approach the real function of the average absorption rate of increase. The Lagrange polynomial approach was used as one of the simple methods of polynomial interpolation with a small margin of error. The Lagrange interpolation polynomial is a polynomial of degree $n$, which passes through $(n+1)$ points and is defined by the following equation [36]:

$$
P(x)=\sum_{j=0}^{n} y_{j} P_{j}(x),
$$

where 


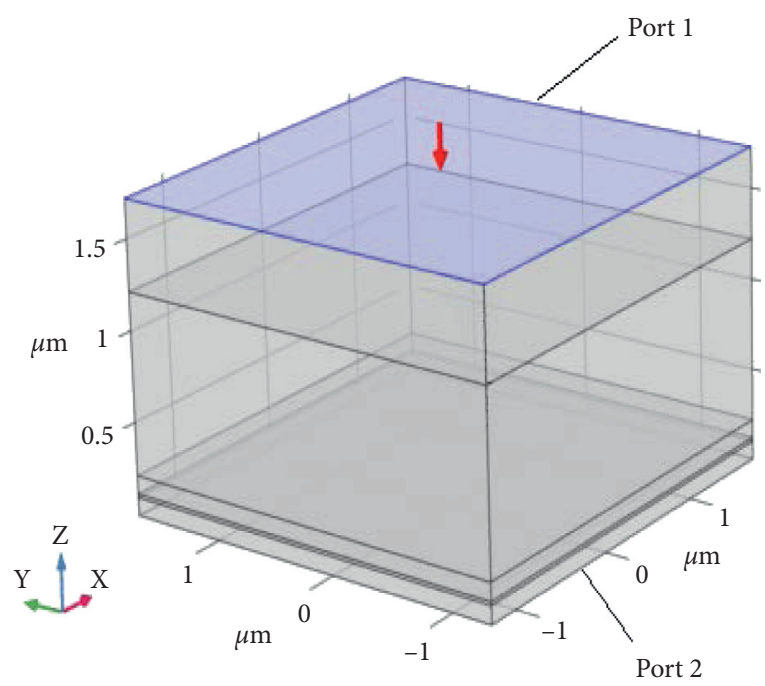

(a)

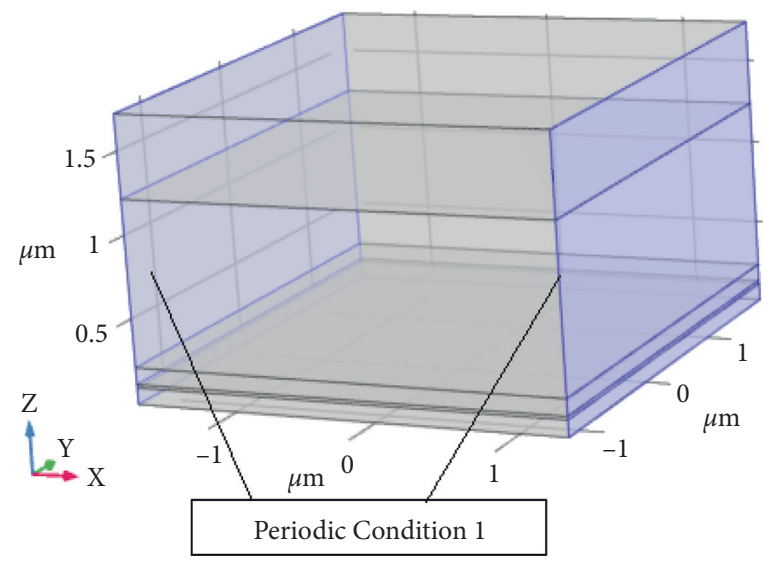

(c)

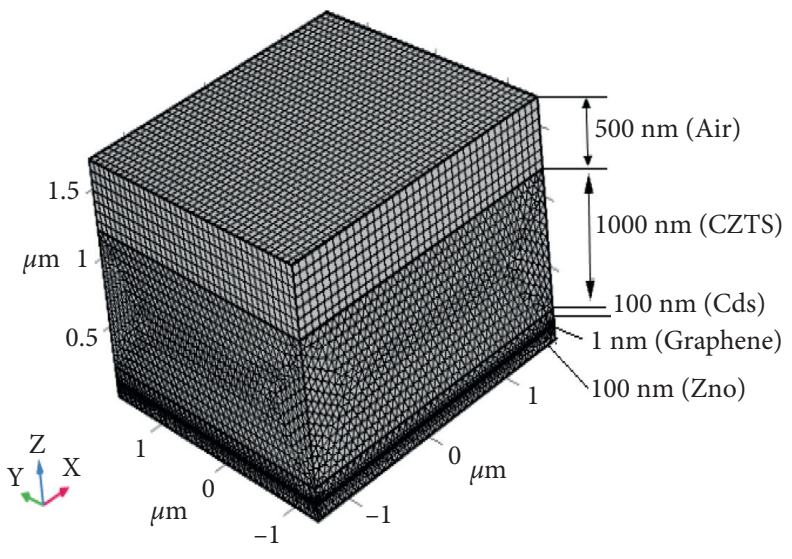

(e)

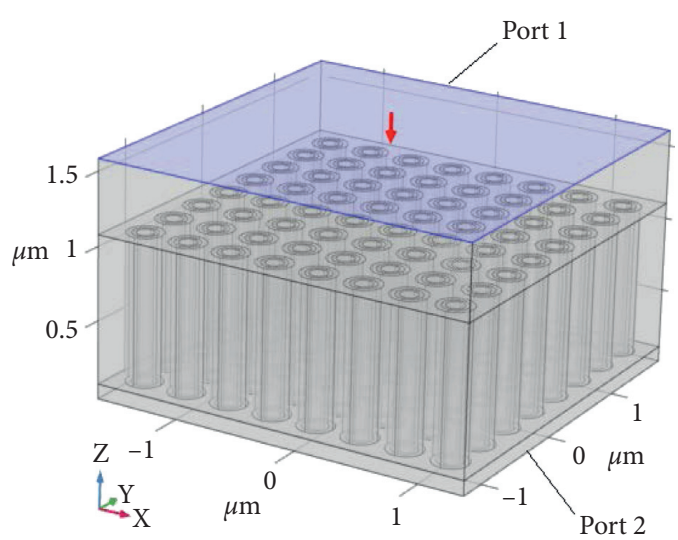

(b)

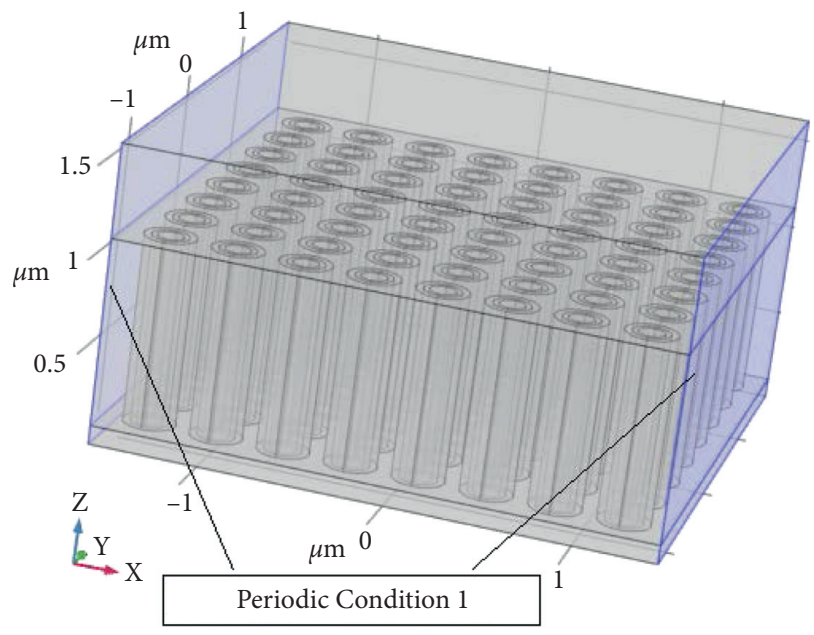

(d)

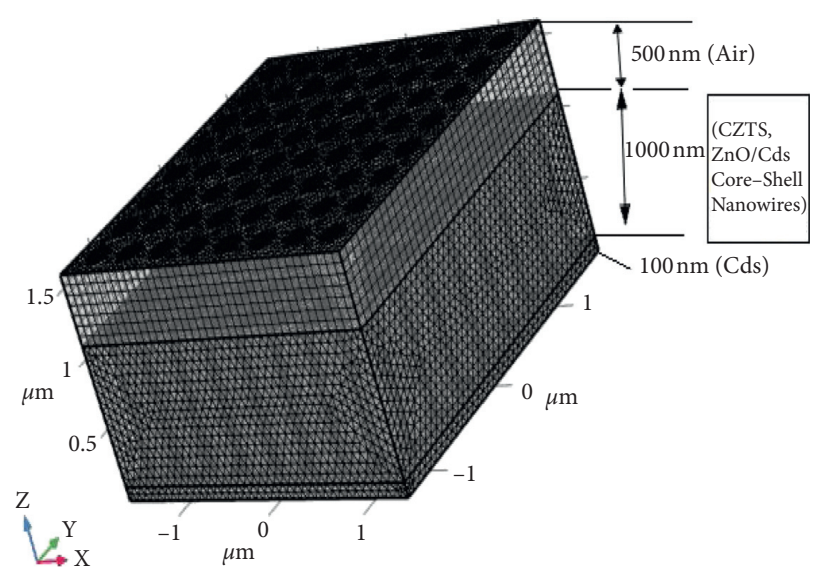

(f)

FIGURE 3: Schematic structure of simulation models: $(\mathrm{a}, \mathrm{b})$ schematic diagrams of the location of the port, respectively, of thin-film and $\mathrm{ZnO} /$ CdS core-shell nanowire models; (c, d) schematic diagram, respectively, of the periodic conditions of thin-film and $\mathrm{ZnO} / \mathrm{CdS}$ core-shell nanowire models; and (e, f) schematic diagram, respectively, of meshing of thin-film and $\mathrm{ZnO} / \mathrm{CdS}$ core-shell nanowire models. 


$$
P_{j}(x)=\prod_{k=0 ; k \neq j}^{n}\left(\frac{x-x_{k}}{x_{j}-x_{k}}\right)
$$

and

$$
y_{0}=f\left(x_{0}\right), y_{1}=f\left(x_{1}\right), y_{2}=f\left(x_{2}\right), \ldots, y_{n}=f\left(x_{n}\right),
$$

where $f(x)$ represents the real interpolated function. The curve of the average absorption rate of increasing $\left(R_{i}\right)$ in the $\mathrm{ZnO} / \mathrm{CdS}$ core-shell nanowires of CdS shell thickness of index $i$ was calculated and plotted by the OriginPro simulation software. This result allowed us to determine the $\mathrm{CdS}$ shell thickness corresponding to the maximum average absorption rate of increase. Our basic model uses $8 \times 8$ nanowires of $1,000 \mathrm{~nm}$ height distributed over a square surface of $9 \mu \mathrm{m}^{2}$ [10]. The refractive indices of CdS, $\mathrm{ZnO}$, and graphene were obtained from the website of the database of refractive indices of materials [37]. The refractive index of CZTS was extracted from the experience of Nabeel A. Bakr et al. and processed by the WebPlotDigitizer simulator $[7,38]$. The bandgap of graphene was very weak, close to 0 , as available on the Wikipedia site [39].

\section{Results and Discussion}

The bandgap of the CdS is a little high; a reduction in its shell thickness would favor the performance of the solar cell, but a very thin shell thickness of CdS does not promote an increase in optical transmission loss either and is technologically difficult to achieve at certain values. The optimal thickness of the CdS shell for good absorption, obtained by simulation, is $40 \mathrm{~nm}$. The multislice representation was chosen to observe better behavior of the parameters in $3 \mathrm{D}$ inside the model.

Figure 4 shows the results of the simulation of the electric field in a 3D multislice with a wavelength of $500 \mathrm{~nm}$ and an angle of incidence of $0^{\circ}$. These results are shown for the thinfilm model in Figure 4(a), for the nanowire model with a CdS shell thickness of $30 \mathrm{~nm}$ in Figure 4(b), for the nanowire model with a CdS shell thickness of $70 \mathrm{~nm}$ in Figure 4(c), for the nanowire model without CdS shell thickness in Figure $4(\mathrm{~d})$, and for the nanowire model with a CdS shell thickness of $100 \mathrm{~nm}$ in Figure 4(e). It is noted that the electric fields above and below the model are, respectively, on an average of $0.46 \times 10^{3}$ and $0.44 \times 10^{3} \mathrm{~V} / \mathrm{m}$ for the thin film (Figure $4(\mathrm{a})$ ); $0.8 \times 10^{3}$ and $0.6 \times 10^{3} \mathrm{~V} / \mathrm{m}$ for the CdS shell thickness of $30 \mathrm{~nm}$ (Figure $4(\mathrm{~b})$ ); $0.6 \times 10^{3}$ and $0.5 \times 10^{3} \mathrm{~V} / \mathrm{m}$ for the CdS shell thickness of $70 \mathrm{~nm}$ (Figure $4(\mathrm{c})$ ); $0.47 \times 10^{3}$ and $0.43 \times 10^{3} \mathrm{~V} / \mathrm{m}$ for the CdS shell thickness of $0 \mathrm{~nm}$ (Figure $4(\mathrm{~d})$ ); and $0.5 \times 10^{3}$ and $0.46 \times 10^{3} \mathrm{~V} / \mathrm{m}$ for the CdS shell thickness of $100 \mathrm{~nm}$ (Figure $4(\mathrm{e})$ ).
It is then observed that the values of the electric field inside and outside the model are different. It is maximum at the surface of the model. Its value increases as the core-shell thickness decreases. This might be due to the fact that as the thickness of the CdS core-shell decreases, the volume of air trapped in the model increases. Since the permittivity of air is lower than that of $\mathrm{CdS}$, the average permittivity decreases [40]. Consequently, the electric field for the core-shell thickness of $30 \mathrm{~nm}$ is greater than that of the core-shell thickness of $70 \mathrm{~nm}$. On the other hand, a very low, even negligible, value of the core-shell thickness (example $0 \mathrm{~nm}$ ) results in a relatively weak electric field and less light trapping. This results in poor performance of the solar cell. On the other hand, a very low, even negligible, value of the core-shell thickness (example $0 \mathrm{~nm}$ ) results in a relatively weak electric field and less light trapping. This results in poor performance of the solar cell.

Figure 5 shows the absorption curves for CdS shell thickness of $30 \mathrm{~nm}$ (blue curve), CdS shell thickness of $70 \mathrm{~nm}$ (green curve), CdS shell thickness (black curve), CdS shell thickness of $100 \mathrm{~nm}$ (cyan curve), and thin-film (red curve) models with an angle of incidence $\theta=0^{\circ}$ as a function of the wavelength, from 200 to $2,000 \mathrm{~nm}$. It was noted that in the ultraviolet region from 200 to $400 \mathrm{~nm}$, the absorption for the thin-film model is, on average, highest among all. This can be attributed to the improvement in the absorption of the thin-film model compared to the nanowire model. On the other hand, in the infrared region $(>700 \mathrm{~nm})$, the small CdS shell thickness has the best absorption, which might be due to the lower fill factor (FF) compared to the other nanowires and a large coefficient of trapping of solar rays in nanowires [41-43]. The maximum absorption is $97 \%$ that was obtained at a wavelength of $500 \mathrm{~nm}$ for a CdS shell thickness of $30 \mathrm{~nm}$.

Figure 6 shows the reflection for CdS shell thickness of $30 \mathrm{~nm}$ (blue curve), CdS shell thickness of $70 \mathrm{~nm}$ (green curve), CdS shell thickness (black curve), CdS shell thickness of $100 \mathrm{~nm}$ (cyan curve), and thin-film (red curve) models with an angle of incidence $\theta=0^{\circ}$ as a function of the wavelength, from 200 to $2,000 \mathrm{~nm}$. It was found that having greater CdS shell thicknesses and thin-film showed, on average, the highest reflection due to a higher FF filling factor [43]. According to Figure 6, the lowest maximum reflection is obtained with the shell thickness of $30 \mathrm{~nm}$, which is $40 \%$, due to more being light trapped in the nanowires [11].

According to the relationship (7), the average absorption rate of increase was calculated for each of the shell thicknesses $0,30,70$, and $100 \mathrm{~nm}$ of the CdS core-shell nanowires compared to a thin film, using integrated function in Comsol by entering it in "Variables" of "Global definition." The results presented in Table 1 were obtained 


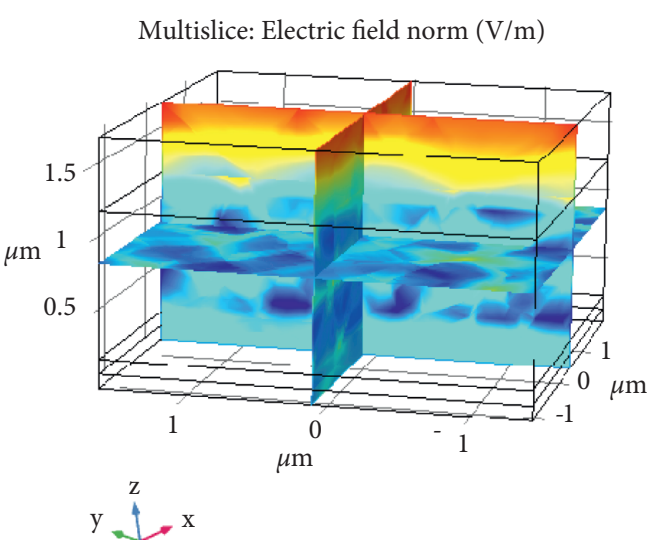

(a)

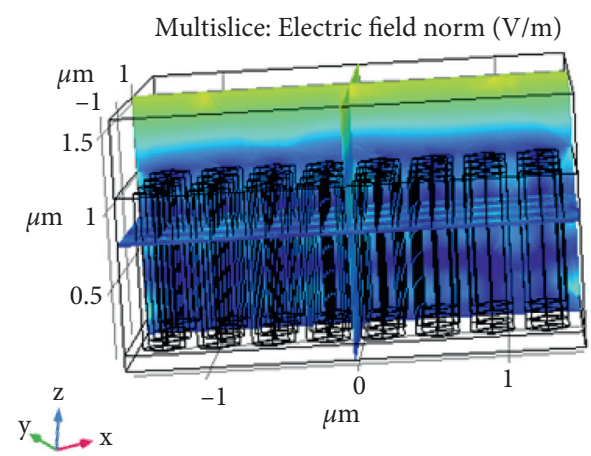

(c)
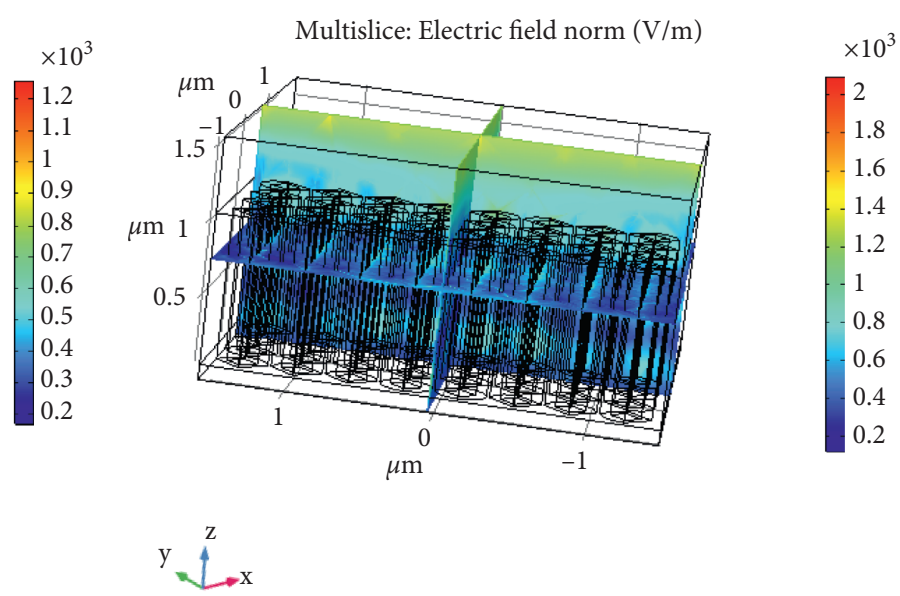

(b)

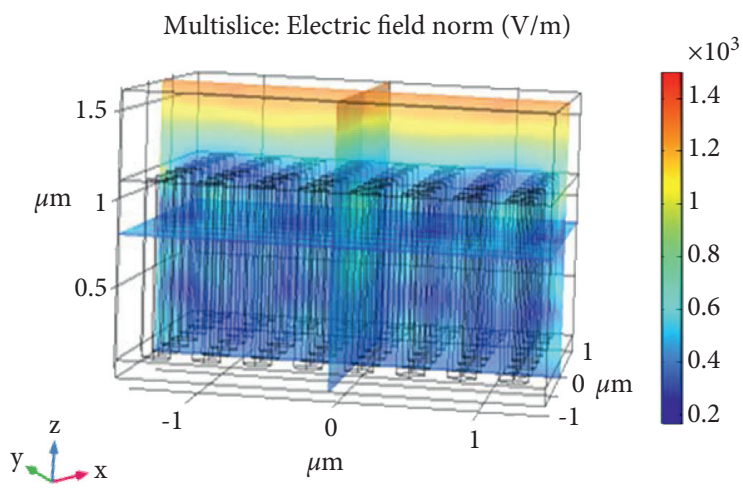

(d)

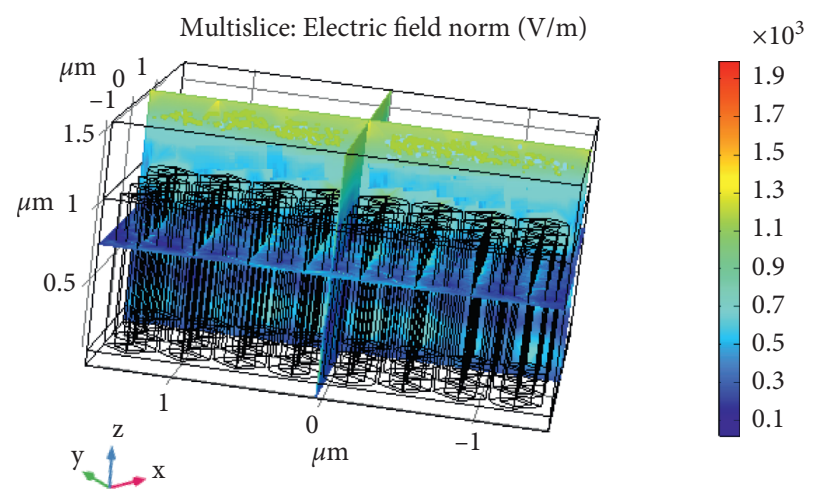

(e)

FIGURE 4: The electric field of (a) thin film, (b) CdS shell thickness of $30 \mathrm{~nm}$, (c) CdS shell thickness of $70 \mathrm{~nm}$, (d) CdS shell thickness of $0 \mathrm{~nm}$ (without CdS shell thickness), and (e) CdS shell thickness of $100 \mathrm{~nm}$.

using the "Global Evaluation" of "Derived Values" in the "Results" section.

After having obtained the average absorption rate of increase as a function of the thickness of the CdS shell, the absorption ratio was approximated over the suitable polynomial function. It was preceded to Lagrange polynomial interpolation according to the relationships (7) and (8), as given as follows: 


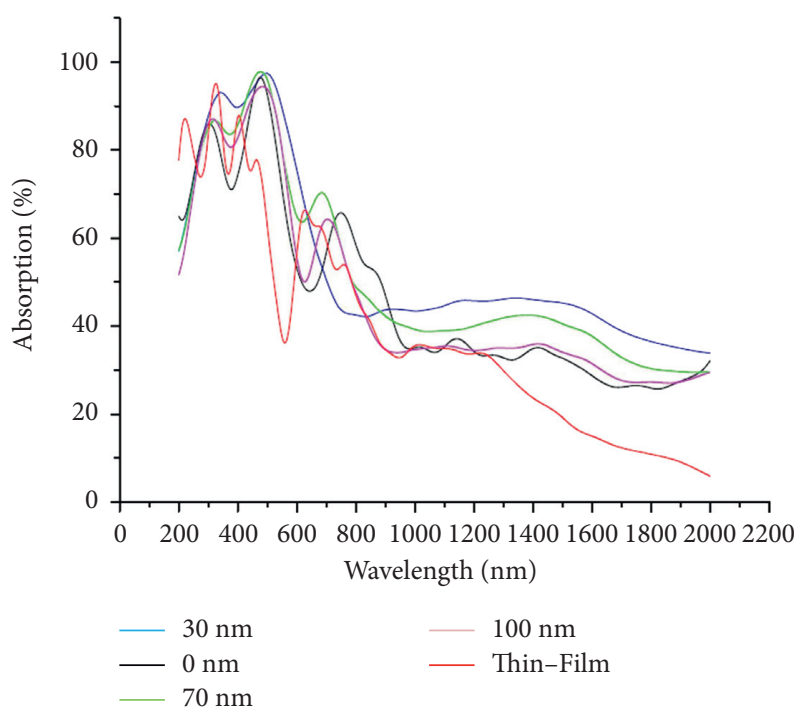

Figure 5: Absorption as a function of wavelength for thin-film (red curve), CdS shell thickness of $30 \mathrm{~nm}$ (blue curve), CdS shell thickness of $70 \mathrm{~nm}$ (green curve), CdS shell thickness (black curve), and CdS shell thickness of $100 \mathrm{~nm}$ (cyan curve).

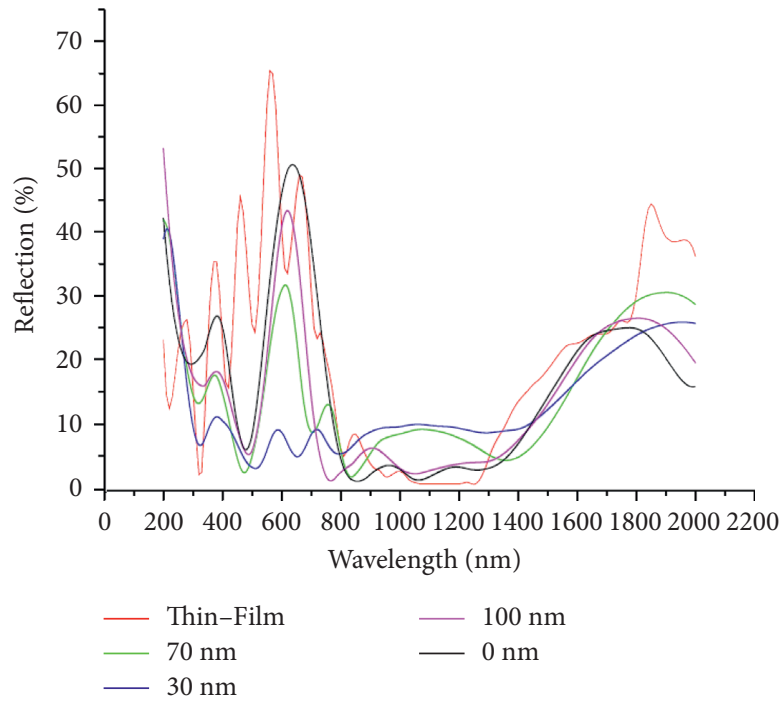

FIGURE 6: Reflection as a function of wavelength for thin-film (red curve), CdS shell of $30 \mathrm{~nm}$ (blue curve), CdS shell of $70 \mathrm{~nm}$ (green curve), CdS shell thickness (black curve), and CdS shell of $100 \mathrm{~nm}$ (light blue curve).

TABLE 1: The average absorption rate of increase for the shell thicknesses of $0 \mathrm{~nm}, 30 \mathrm{~nm}, 70 \mathrm{~nm}$, and $100 \mathrm{~nm}$ of the CdS core-shell nanowires compared to a thin film.

Shell thickness

$0 \mathrm{~nm}$

$30 \mathrm{~nm}$

$70 \mathrm{~nm}$

$100 \mathrm{~nm}$

Average absorption rate of increase, $R_{i}(\%)$

20.14

39.25

32.33

20.55




$$
\begin{aligned}
P_{0}(x) & =\frac{x-30}{0-30} \frac{x-70}{0-70} \frac{x-100}{0-100} \\
P_{1}(x) & =\frac{x-0}{30-0} \frac{x-70}{30-70} \frac{x-100}{30-100} \\
P_{2}(x) & =\frac{x-0}{70-0} \frac{x-30}{70-30} \frac{x-100}{70-100} \\
P_{3}(x) & =\frac{x-0}{100-0} \frac{x-30}{100-30} \frac{x-70}{100-70}, \\
y_{0} & =20.14 ; y_{1}=39.25 ; y_{2}=32.33 ; y_{3}=20.55 .
\end{aligned}
$$

After this, from relation (8), the following polynomial function was derived:

$P(x)=0.000084 x^{3}-0.0200048 x^{2}+1.16124286 x+20.14$.

The error generated was $\varepsilon=\left|P\left(x_{j}\right)-f\left(x_{j}\right)\right|$ with $j \in\{0 ; 1 ; 2 ; 3\}$. The errors obtained are given in Table 2 . In Table $2, \mathbf{f}\left(\mathbf{x}_{\mathbf{j}}\right)=\mathbf{R}_{\mathbf{i}}$ the highest error was $0.33 \%$. The polynomial approximation curve $P(x)$ given in Figure 7 is plotted using OriginPro.

The maximum interpolating function $P(x)$ of $39.95 \%$ was obtained at the CdS shell thickness of $40 \mathrm{~nm}$. Therefore, the best CdS shell thickness for high optical absorption is $40 \mathrm{~nm}$, while the value at $30 \mathrm{~nm}$ is very lower than this. Figure 8 shows the transmission curve for CdS shell thickness of $30 \mathrm{~nm}$ (blue curve), CdS shell thickness of $70 \mathrm{~nm}$ (green curve), CdS shell thickness (black curve), CdS shell thickness of $100 \mathrm{~nm}$ (cyan curve), and thin-film (red curve) model with an angle of incidence $\theta=0^{\circ}$, as a function of the wavelength, from $200 \mathrm{~nm}$ to $2,000 \mathrm{~nm}$. It was clear that in the visible light region the $\mathrm{CdS}$ shell thicknesses showed the maximum absorption among all, while it was lowest in the case of $30 \mathrm{~nm}$, that is, the higher the shell thickness, the more the transmission in the visible light region, which is in conformance with the previous studies on the solar cells as well [43]. The curve of the thin-film model was close to that of the $100 \mathrm{~nm}$ shell thicknesses. The lowest transmission was observed for the nanowires with a shell thickness of $30 \mathrm{~nm}$, having maximum transmission of $54 \%$ at a wavelength of $800 \mathrm{~nm}$.

Figure 9 shows the current density as a function of voltage under light illumination for CdS shell thickness of $30 \mathrm{~nm}$ (blue curve), CdS shell thickness of $70 \mathrm{~nm}$ (green curve), CdS shell thickness (black curve), CdS shell thickness of $100 \mathrm{~nm}$ (cyan curve), and thin-film (red curve) devices. The smallest CdS shell thicknesses have the best current density. This can be explained in terms of the drop in reflection parasitic losses and the photogeneration of the speed profile of the electron-hole pairs excited in these CdS shell thicknesses [44]. In this case, the average absorption and reflection are, respectively, higher and moderate.

Table 3 shows the numerical values of short current density (Jsc), open-circuit voltage (Voc), efficiency (EFF), and FF for thin-film and core-shell nanowire devices.
TABLE 2: Errors obtained by Lagrange polynomial approximation.

\begin{tabular}{lcccc}
\hline$j$ & 0 & 1 & 2 & 3 \\
$\mathbf{x}_{\mathbf{j}}(\mathrm{nm})$ & 0 & 30 & 70 & 100 \\
$\mathbf{f}\left(\mathbf{x}_{\mathbf{j}}\right)(\%)$ & 20.14 & 39.25 & 32.33 & 20.55 \\
$\mathbf{P}\left(\mathbf{x}_{\mathbf{j}}\right)(\%)$ & 20.14 & 39.24 & 32.22 & 20.22 \\
$\varepsilon(\%)$ & 0 & 0.01 & 0.11 & 0.33 \\
\hline
\end{tabular}

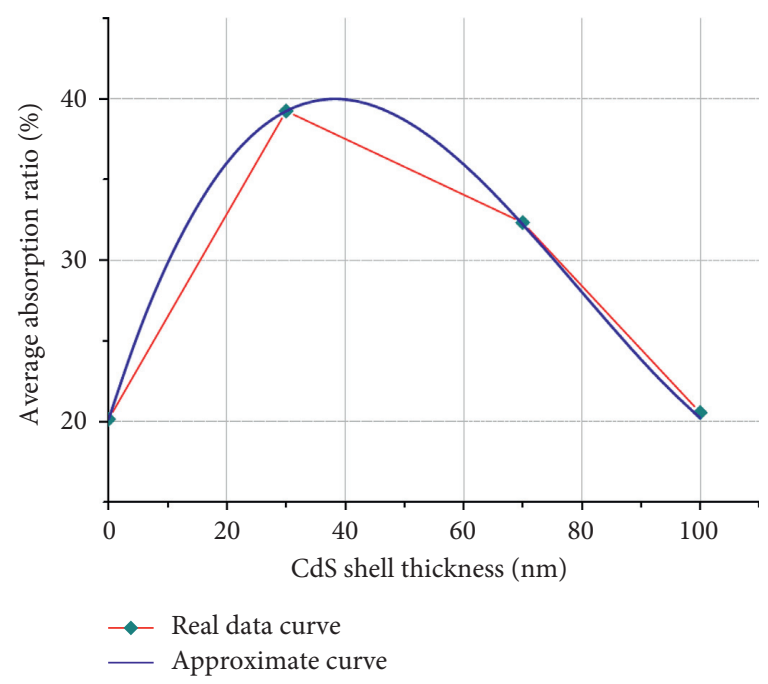

FIgURE 7: The average absorption rate of increase as a function of CdS shell thickness.

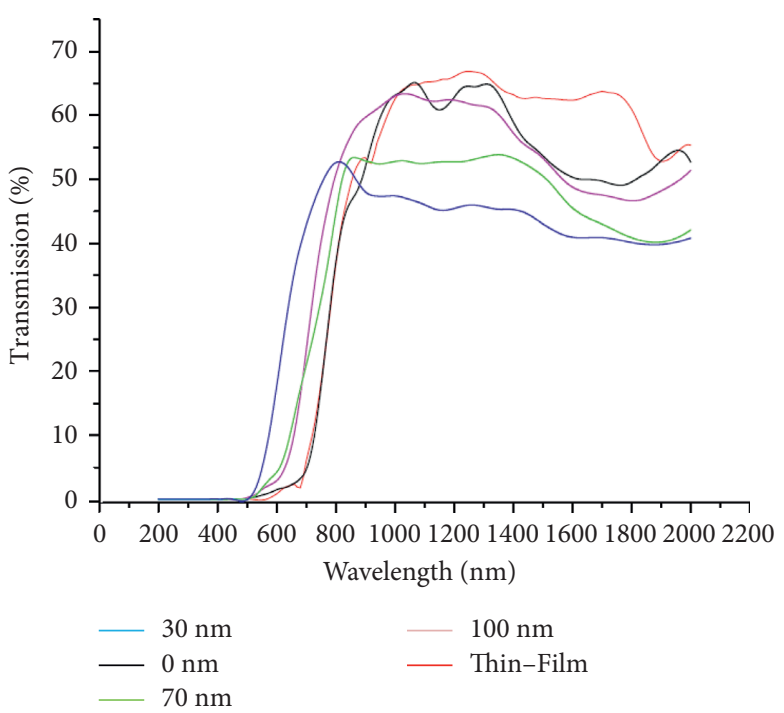

FIgURE 8: Transmission as a function of wavelength for thin-film (red curve), CdS shell thickness of $30 \mathrm{~nm}$ (blue curve), CdS shell thickness of $70 \mathrm{~nm}$ (green curve), CdS shell thickness (black curve), and CdS shell thickness of $100 \mathrm{~nm}$ (cyan curve).

Thus, the best performance was obtained for the CdS shell thickness of $30 \mathrm{~nm}$, with efficiency (EFF) of $16.8 \%$, a short-circuit current density (Jsc) of $6.39 \mathrm{~mA} / \mathrm{cm}^{2}$, and an open-circuit voltage (Voc) of $630 \mathrm{mV}$. The short-circuit current density, the open-circuit voltage, and the efficiency 


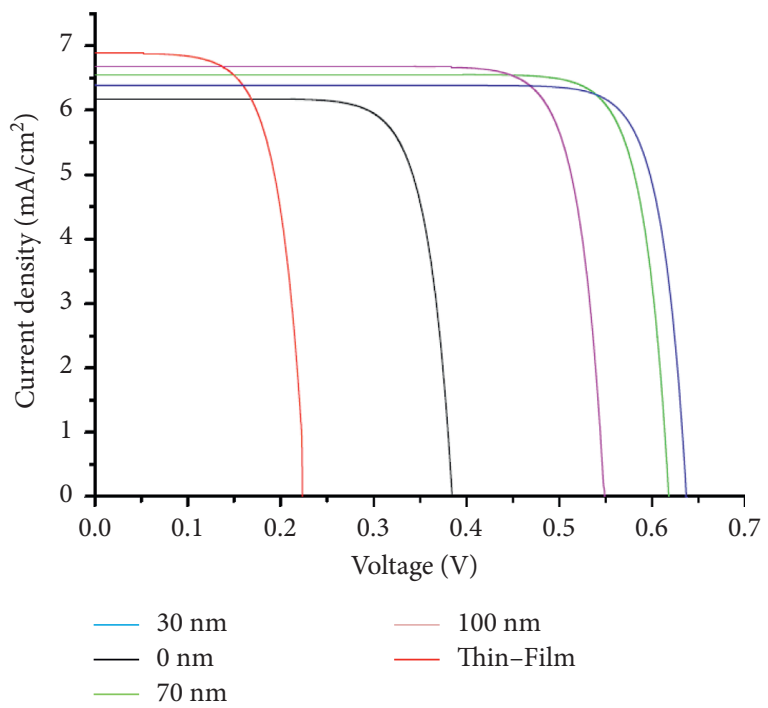

FIGURE 9: Current density as a function of voltage for thin-film (red curve), CdS shell thickness of $30 \mathrm{~nm}$ (blue curve), CdS shell thickness of $70 \mathrm{~nm}$ (green curve), CdS shell thickness (black curve), and CdS shell thickness of $100 \mathrm{~nm}$ (cyan curve).

TABLE 3: The numerical values of Jsc, Voc, FF, and EFF for thin-film and core-shell nanowire devices.

\begin{tabular}{lccccc}
\hline \multicolumn{1}{c}{ Model sol. cell } & $\begin{array}{c}V_{\mathrm{oc}} \\
(V)\end{array}$ & $\begin{array}{c}\mathrm{Jsc} \\
\left(\mathrm{mA} / \mathrm{cm}^{2}\right)\end{array}$ & $\begin{array}{c}\text { FF } \\
(\%)\end{array}$ & $\begin{array}{c}\text { EFF } \\
(\%)\end{array}$ \\
& $0 \mathrm{~nm}$ & 0.38 & 6.17 & 6.60 & 15.7 \\
CdS shell & $30 \mathrm{~nm}$ & 0.63 & 6.39 & 4.12 & 16.8 \\
thickness & $70 \mathrm{~nm}$ & 0.61 & 6.54 & 4.10 & 16.6 \\
& $100 \mathrm{~nm}$ & 0.54 & 6.67 & 4.40 & 16.1 \\
Thin film & & 0.22 & 6.88 & 8.75 & 13.5 \\
\hline
\end{tabular}

for thin-film are, respectively, $6.88 \mathrm{~mA} / \mathrm{cm}^{2} ; 220 \mathrm{mV}$; and $13.5 \%$. An improvement in the performance of these models was noted due to certain physical and chemical properties, such as electronic mobility, conductivity, photocurrent generation, the use of graphene in the models, and so on. In the simulation, the layer of $\mathrm{MoS}_{2}$, which was developed during the sulfurization of the back-contact interface of the CZTS, was minimized, as it did not favor the recombination of the charge carriers $[15,43]$. Other experiments carried out on $\mathrm{ZnO} / \mathrm{CdS}\left(\mathrm{Jsc}=3.35 \mathrm{~mA} / \mathrm{cm}^{2}\right.$ and $\left.\mathrm{EFF}=32 \%\right)$ and $\mathrm{ZnO} /$ $\mathrm{CdS} / \mathrm{CuSbS}_{2}(\mathrm{Jsc}=6.48 \mathrm{~mA}, \mathrm{EFF}=52 \%)$ core-shell nanowires are not only similar to our work but our model proved more effective than these are. This might be due to the voltage difference as in the previous studies the results were obtained under $\mathrm{Ag} / \mathrm{AgCl}$ voltage [45]. Three years ago, Gueddim et al. were able to obtain a conversion efficiency of $23.6 \%$ for the $\mathrm{ZnO} / \mathrm{CdS} / \mathrm{CZTS}$ structure with respective thicknesses of $0.1,0.02$, and $1 \mu \mathrm{m}$ and a band of $1.45 \mathrm{eV}$ using SCAPS [22], against $13.5 \%$ for the $\mathrm{ZnO}$ /graphene/CdS/ CZTS thin-film model and $16.8 \%$ for the $\mathrm{ZnO} / \mathrm{CdS}$ coreshell nanowire arrays model in a CZTS absorber that we have proposed. But, according to the literature, SCAPS cannot directly manage multijunction structures; the solution is to calculate the top and bottom cells separately [46]. Add to this that SCAPS, like 1D software, assumes a perfect similitude of the behavior of the three components $(x, y$, and $z$ ) of the parameters. 3D simulation, in particular with COMSOL Multiphysics, makes it possible to process the parameters according to the three axes, and the results obtained are close to physical reality. The difference in the values of the two models of thin-film can probably be due to the dependence of the axes $(x, y$, and $z)$ of the evolution of the components of certain parameters such as current density, electric and magnetic fields, permittivity relative, and so on. Recall that a few years ago, Qian Liu et al. were able to obtain because of the 3D simulation software, Ansoft HFSS14, an absorption rate of about $90 \%$ over the frequency range of 300 to $750 \mathrm{THz}$, corresponding approximately to a wavelength interval of $400 \mathrm{~nm}$ to $1,000 \mathrm{~nm}$ [47] in the study of a periodic network of double-shell nanowire structures ( $\mathrm{ZnO} / \mathrm{CdS} / \mathrm{CZTS}$ ) embedded in a thin multilayer film [48]. These results are close to those of our model with the $\mathrm{ZnO} /$ $\mathrm{CdS}$ core-shell nanowires, but the introduction of a layer of graphene between the $\mathrm{ZnO}$ core and the $\mathrm{CdS}$ shell allowed us to obtain an absorption rate of $97 \%$ at a wavelength of about $500 \mathrm{~nm}$. This nanowire core-shell model proposed in this work can therefore play an interesting role in the fabrication of solar cells with broadband light absorption rate $[47,48]$. It also shows that this model is very cost-effective in visible spectrum regions [49].

\section{Conclusions and Recommendations}

This simulation study of the CZTS solar cell based on thinfilm, and $\mathrm{ZnO} / \mathrm{CdS}$ core-shell nanowire arrays with a CZTS absorber was carried out with the objective of defining the optimal CdS shell thickness for better optical and electrical performance of the solar cell. The $\mathrm{ZnO} / \mathrm{CdS}$ core-shell nanowires with CdS shell thicknesses of $30 \mathrm{~nm}$ and $40 \mathrm{~nm}$ obtained the best performance. For these nanowire models, the short-circuit current density (Jsc) and open-circuit voltage (Voc) are $630 \mathrm{mV}$ and $6.39 \mathrm{~mA} / \mathrm{cm}^{2}$, respectively, with an average absorption rate of increase of $39.95 \%$. These improved functions are due to the significant trapping of light in these nanowires of small shell thicknesses around $30 \mathrm{~nm}$. Thus, the minimum reflection and maximum transmission of $40 \%$ and $54 \%$, respectively, were obtained for the shell thickness of $30 \mathrm{~nm}$. The relationship from the Lagrange polynomial approach, based on the average absorption rate of increase as compared to the thin film and the shell thickness, is proposed to be used in all models of $\mathrm{ZnO} /$ $\mathrm{CdS}$ core-shell nanowires with a $\mathrm{ZnO}$ core having a diameter of $100 \mathrm{~nm}$, the height of $1,000 \mathrm{~nm}$, and a nanowire pitch of $360 \mathrm{~nm}$, in order to determine the optimal CdS shell thickness. It will avoid the excessive use of the CdS material and thus reduce the manufacturing cost of the solar cell. Thus, with the selection of optimal CdS shell thickness of the nanowire model and the use of graphene between the CdS and $\mathrm{ZnO}$ layers, an improvement in the efficiency of both models (13.5\% for thin-film and $16.8 \%$ for $\mathrm{ZnO} / \mathrm{CdS}$ coreshell nanowire models) was achieved. The use of the nanowire core-shell model proposed in this study would be very cost-effective in designing solar cells with broadband light absorption rate and useful in visible spectrum regions. 


\section{Data Availability}

The data used to support the findings of this study are included within the article.

\section{Conflicts of Interest}

The authors declare that there are no conflicts of interest.

\section{References}

[1] R. Mahbub, M. S. Islam, F. Anwar, S. S. Satter, and S. M. Ullah, "Simulation of CZTS thin-film solar cell for different buffer layers for high-efficiency performance," South Asian Research Journal of Engineering and Technology (SARJET), vol. 2, no. 52, pp. 1-10, 2016.

[2] A. Benami, "Effect of CZTS parameters on photovoltaic solar cell from numerical simulation," Journal of Energy and Power Engineering, vol. 13, pp. 32-36, 2019.

[3] G. K. Gupta and A. Dixit, "Simulation studies of CZT(S, Se) single and tandem junction solar cells towards possibilities for higher efficiencies up to 22\%," 2018, https://arxiv.org/abs/ 1801.08498.

[4] Dr.V. K. Sethi, Dr. M. Pandey, and Ms. P. Shukla, "Use of nanotechnology in solar PV cell," International Journal of Chemical Engineering Applications, vol. 2, no. 2, 2011.

[5] K. Jimbo, R. Kimura, T. Kamimura et al., "Cu2ZnSnS4-type thin-film solar cells using abundant materials," Thin Solid Films, vol. 515, no. 15, pp. 5997-5999, 2007.

[6] J. Wang, X. Xin, and Z. Lin, "Cu2ZnSnS4 nanocrystals and graphene quantum dots for photovoltaics," Nanoscale, vol. 3, no. 8, pp. 3040-3048, 2011.

[7] N. A. Bakr, Z. T. Khodair, and H. I. Mahdi, "Influence of thiourea concentration on some physical properties of chemically sprayed $\mathrm{Cu} 2 \mathrm{ZnSnS4}$ thin films," International Journal of Materials Science and Applications, vol. 5, no. 6, pp. 261-270, 2016.

[8] S. I. Swati, R. Matin, S. Bashar, and Z. H. Mahmood, "Experimental study of the optical properties of $\mathrm{Cu} 2 \mathrm{ZnSnS4}$ thinfilm absorber layer for solar cell application," Journal of Physics: Conference Series, vol. 1086, no. 1, 2018.

[9] H. Katagiri, K. Jimbo, S. Yamada et al., "Enhanced conversion efficiencies of $\mathrm{Cu} 2 \mathrm{ZnSnS4-based} \mathrm{thin} \mathrm{film} \mathrm{solar} \mathrm{cells} \mathrm{by} \mathrm{using}$ preferential etching technique," Applied Physics Express, vol. 1, no. 4, Article ID 041201, 2008.

[10] W. Sun, M. Brozak, J. C. Armstrong, and J. Cui, "Solar cell structures based on $\mathrm{ZnO} / \mathrm{CdS}$ core-shell nanowires arrays embedded in Cu2ZnSnS4 light absorber," in Proceedings of the IEEE Photovoltaic Specialists Conference (PVSC), pp. 20422046, Tampa, FL, USA, June 2013.

[11] J. Michallon, D. Bucci, A. Morand, M. Zanuccoli, V. Consonni, and A. Kaminski-Cachopo, "Light trapping in $\mathrm{ZnO}$ nanowire arrays covered with an absorbing shell for solar cells," Optics Express, vol. 22, no. S4, pp. A1174-A1189, 2014.

[12] F. Anwar, "Simulation and performance study of nanowires CdS/CdTe solar cell," International Journal of Renewable Energy Resources, vol. 7, no. 2, 2016.

[13] N. Gouthami, D. Parthiban, M. Alagappan, and G. Anju, "Design and simulation of 3d zno nanowire based gas sensor for conductivity studies," in Proceedings of the Comsol conference in Bangalore, Boston, Stuggart,Bangalore, 2011.

[14] M. M. Don, C. Y. San, and J. Jeevanandam, "Antimicrobial properties of nanobiomaterials and the mechanism,"
Nanobiomaterials in Antimicrobial Therapy, vol. 6, pp. 261312, 2016.

[15] S. Khanchandani, S. Kundu, A. Patra, and A. K. Ganguli, "Shell thickness dependent photocatalytic properties of $\mathrm{ZnO} /$ CdS core-shell nanorods," Journal of Physical Chemistry C, vol. 116, no. 44, pp. 23653-23662, 2012.

[16] K. Kumar, S. Pattanaik, and Dr. S. K. Dash, "Modelling of the nanowires CdS-CdTe device design for enhanced quantum efficiency in window absorber type solar cells," International Journal of Scientific Research and Management, vol. 07, pp. 2279-543X, 2019.

[17] R. Chen, J. Fan, C. Liu, X. Zhang, Y. Shen, and Y. Mai, "Solution-processed one-dimensional ZnO@CdS heterojunction toward efficient $\mathrm{Cu} 2 \mathrm{ZnSnS} 4$ solar cell with inverted structure," Scientific Reports, vol. 6, p. 35300, 2016.

[18] M. Ding, N. Yao, C. Wang et al., “ZnO@CdS core-shell heterostructures: fabrication, enhanced photocatalytic, and photoelectrochemical performance," Nanoscale Research Letters, vol. 11, no. 1, p. 205, 2016.

[19] J. Kim Dinh Hoang, "The core-shell nanowire as a solar cell," 2014, http://www.lmpv.nl/wp-content/uploads/2016/10/BScthesis-2014-John-Huong.pdf.

[20] Q. Li, H. Yu, Y. Cui et al., "Effect of sulfurization temperature on the preparation of $\mathrm{Cu} 2 \mathrm{ZnSnS4}$ thin films for solar cells via a nanoink coating method," International Journal of Electrochemical Science, vol. 16, Article ID 210558, 2021.

[21] T. Edwards, Optimisation of Coated Nanowire Solar Cells by Simulationhttps://spiral.imperial.ac.uk/bitstream/10044/1/ 34928/3/Edwards-T-2016-PhD-Thesis.pdf, Imperial College London, London, UK, 2016, https://spiral.imperial.ac.uk/ bitstream/10044/1/34928/3/Edwards-T-2016-PhD-Thesis. pdf.

[22] A. Gueddim, N. Bouarissa, A. Naas, F. Daoudi, and N. Messikine, "Characteristics and optimization of $\mathrm{ZnO} / \mathrm{CdS} /$ CZTS photovoltaic solar cell," Applied Physics A, vol. 124199 pages, 2018.

[23] S. Alhammadi, V. R. M. Reddy, S. Gedi et al., "Performance of graphene-CdS hybrid nanocomposite thin film for applications in $\mathrm{Cu}(\mathrm{in}, \mathrm{Ga}) \mathrm{Se} 2$ solar cell and $\mathrm{H} 2$ production," Nanomaterials, vol. 10, no. 2, 245 pages, 2020.

[24] M. Saranya, R. Ramachandran, and F. Wang, "Graphene-zinc oxide $(\mathrm{G}-\mathrm{ZnO})$ nanocomposite for electrochemical supercapacitor applications," Journal of Science: Advanced Materials and Devices, vol. 1, no. 4, pp. 454-460, 2016.

[25] M. Jabeen and S. Haxha, "High rear reflectance and light trapping in textured graphene-based silicon thin-film solar cells with back dielectric-metal reflectors," OSA Continuum, vol. 2, no. 5, 2019.

[26] Oriel Product Training, "Solar simulation," 2015, https:// www.newport.com/medias/sys_master/images/images/h9c/ hea/8797264445470/Solar-Simulation.pdf.

[27] Comsol Multiphysics, "Introduction to Comsol Multiphysics," Comsol, vol. 5.3, pp. 6-153, 2017.

[28] Comsol Multiphysics, "Semiconductor module user's guide," Comsol, vol. 5.4, pp. 11-264, 2018.

[29] M. Aghaeipour and H. Pettersson, "Enhanced broadband absorption in nanowire arrays with integrated Bragg reflectors," Nanophotonics, vol. 7, no. 5, pp. 819-825, 2018.

[30] H. Guo, L. Wen, X. Li, Z. Zhao, and Y. Wang, "Analysis of optical absorption in GaAs Nanowires arrays," Nanoscale Research Letters, vol. 6617 pages, 2011.

[31] B. C. P. Sturmberg, K. B. Dossou, L. C. Botten et al., "Modal analysis of enhanced absorption in silicon nanowire arrays," Optics Express, vol. 19, no. S5, 2011. 
[32] O. Breitenstein, "Understanding the current-voltage characteristics of industrial crystalline silicon solar cells by considering inhomogeneous current distributions," Opt. El. Review, vol. 21, no. 3, pp. 259-282, 2013.

[33] Rf Module, "User's guide," Comsol Multiphysics, vol. 5.3, 1998-2017.

[34] Math Open Reference, "On the average value," 2011, https:// www.mathopenref.com/calcaveval.html.

[35] C. J. F. Burns, "On calculating percent increase and decrease," 2021, https://www.onemathematicalcat.org/algebra_book/ online_problems/calc_percent_inc_dec.htm.

[36] K. A. Hussien, "The Lagrange interpolation polynomial for neural network learning," IJCSNS International Journal of Computer Science and Network Security, vol. 11, no. 3, 2011.

[37] "Material refractive index database," 2021, https:// refractiveindex.info/.

[38] A. Rohatgi, "User manual," 2020, https://automeris.io/ WebPlotDigitizer/userManual.pdf.

[39] "Graphene, the free encyclopedia," 2021, https://en.wikipedia. org/wiki/Graphene\#: :text=Graphene's\%20band\%20gap\% 20can\%20be,by\%20an\%20applied\%20magnetic\%20field.

[40] Electrical4U, "Permittivity and relative permittivity or dielectric constant," 2020, https://www.electrical4u.com/permittivity-andrelative-permittivity-or-dielectric-constant/.

[41] J. Zwinkels, "Light, electromagnetic spectrum," Encyclopedia of Color Science and Technology, vol. 8071, pp. 1-8, 2015.

[42] Jstor, "On the colors of the visible light spectrum," 2017, https://en.wikipedia.org/wiki/Color.

[43] B. Wang, E. Stevens, and P. W. Leu, "Strong broadband absorption in GaAs nanocone and nanowire arrays for solar cells," Optics Express, vol. 22, no. S2, pp. A386-A395, 2014.

[44] L. C. Andreani, A. Bozzola, P. Kowalczewski, M. Liscidini, and L. Redorici, "Silicon solar cells: toward the efficiency limits," Advances in Physics X, vol. 4, no. 1, Article ID 1548305, 2018.

[45] R.-R. Su, Y.-X. Yu, Y.-H. Xiao, X. Yang, and W.-D. Zhang, "Earth-abundant $\mathrm{ZnO} / \mathrm{CdS} / \mathrm{CuSbS}_{2}$ core-shell nanowire arrays as highly efficient photo anode for hydrogen evolution," International Journal of Hydrogen Energy, vol. 43, no. 12, pp. 6040-6048, 2018.

[46] M. Burgelman, K. Decock, A. Niemegeers, J. Verschraegen, and S. Degrave, SCAPS Manual, p. 146, University of Gent, Department of Electronics and Information Systems (ELIS), Ghent, Belgium, 2021.

[47] K. Yur, A. Zolotkov, and U. Convertor, "Convert terahertz $[\mathrm{THz}]$ to wavelength in meters," 2021, https://www. translatorscafe.com/unit-converter/en-US/frequencywavelength/4-27/terahertz-wavelength\%20in\%20metres/.

[48] Q. Liu, E. Sandgren, M. Barnhart, R. Zhu, and G. Huang, "Photonic nanostructures design and optimization for solar cell application," Photonics, vol. 2, no. 3, pp. 893-905, 2015.

[49] A. E. Ghitas, "Studying the effect of spectral variations intensity of the incident solar radiation on the Si solar cells performance," NRIAG Journal of Astronomy and Geophysics, vol. 1, no. 2, pp. 165-171, 2012. 